\title{
Measuring the quality of teacher-child interaction in autistic disorder
}

\author{
Claudio Longobardi, Laura Elvira Prino, Tiziana Pasta, Francesca \\ Giovanna Maria Gastaldi and Rocco Quaglia \\ University of Turin (Italy)
}

\begin{abstract}
The teacher-child relationship fulfils critical functions for the well being of the child, affecting emotive development, academic achievements, behavioral conducts and relationships with peers. The goal of the presented study is to compare the perceptions of the class teacher and of the support teacher concerning their relationship with subjects with autistic spectrum disorders (ASD; $N=14$; Mean age $=90.07$ months; $S D=19.36$ ) and with children of the control group (4 classmates per every subject of the experimental group, for a total of 56 pupils, Mean age $=80.36$ months; $S D=18.33$ ). The perception by the teacher of the class, concerning the relationship with children with ASD, is characterized by higher levels of Conflict, and lower levels of Closeness, if compared with perceptions about the relationship with children of the control group (Conflict: $t=-3.317$; $d f=14.931 ; p<0.01$; Closeness: $t=5.638 ; d f=65 ; p<0.001)$. The perception of the two teachers only correlates with regards to the Conflict dimension $(r=0.769 ; p<0.01)$. In reference to the child's adaptive skills only the social skills scale correlates with the Closeness. This is true in the perception of the support teacher $(r=0.598 ; p<0.05)$. Finally, we take into account how the perception of the relationship relates with the socio-personal and professional data of the teachers and with the social features of the children.

Key words: Teacher-child relationship, Autism spectrum disorder, Teaching assistant, Inclusion.
\end{abstract}

Medición cualitativa de la interacción profesor-alumno en el trastorno de autismo. La relación profesor-alumno tiene un rol fundamental para el bienestar del alumno repercutiendo sobre el desarrollo emocional, los logros académicos, el comportamiento y las relaciones con los compañeros. El objetivo de este estudio es comparar las percepciones del profesor de la clase con las del profesor de apoyo sobre su relación con alumnos con trastornos del espectro autista (ASD; $N=14$; edad media $=90,07$ meses; $S D=19,36)$ y con alumnos del grupo de control (4 compañeros por cada alumno del grupo experimental, por un total de 56 alumnos, edad media $=80,36$ meses; $S D=18,33)$. El profesor de la clase tiene una percepción de la relación con alumnos con ASD caracterizada por un mayor nivel de Conflicto y un menor nivel de Cercanía, comparado con la percepción de la relación con alumnos del grupo (Conflicto: $t=-3,317 ; d f=14,931$; $p<0,01$; Cercanía: $t=5,638 ; d f=65 ; p<0,001)$. La percepción de los dos profesores converge solo en la dimensión Conflicto $(r=0,769 ; p<0,01)$. En cuanto a las habilidades de adaptación de los alumnos solamente las habilidades sociales se correlacionan con la Cercanía. Esto se cumple en la percepción del profesor de apoyo $(r=0,598 ; p<0,05)$. Por último consideramos cómo la percepción de la interacción está relacionada con los datos socio-personales y profesionales de los profesores y las características sociales de los alumnos.

Palabras clave: Relación profesor-alumno, Trastorno del Espectro Autista, profesor de apoyo, inclusión.

Correspondence: Claudio Longobardi. Department of Psychology. University of Turin. Via Po 14, Turin (Italy). E-mail: claudio.longobardi@unito.it 
There is wide agreement among developmental psychologists in considering the role of early relationships with adult figures as relevant for the child's developmental processes. Although the relationships with parents will remain the most important and significant ones, the latest empirical data suggest that a child with secure attachment, i.e. sufficiently reassured concerning her safety needs, is characterized by higher willingness to commit in social relationships with other people (Bowlby, 1988), and in particular with educators and teachers (Pianta, Steinberg \& Rollins, 1995). Pianta (1999) proposed a conceptual model that allows researchers for both a better understanding of the nature of the relationship between teachers and children and a deeper knowledge of the role of such relationships in the child's development. Most of the research on the teacher-pupil relationship is based on the teacher's perception of the relationship. A well-known instrument to evaluate these perceptions is the Student-Teacher Relationship Scale (STRS; Pianta, 2001) throughout which teachers can evaluate their own relations with specific students concerning three investigated dimensions: closeness, dependency and conflict. Closeness refers to the degree of interaction and to a warm, open and positive communication between the teacher and the child. On the contrary, Dependency and Conflict are dimensions which qualify a relationship as negative; in particular, the students' excessive dependence on their teachers would characterize a relationship betraying the presence of anger and sullenness (Pianta, 2001). Good relationships with teachers as thus identified by a combination of high levels of closeness and low levels of conflict.

Conceiving relationships as dyadic constructs, we hypothesize that understanding how teachers perceive their relationships with children during the first school years might be crucial in order to promote a higher well-being within the classroom. The quality of the teacher-child relationship relies not only on the personal characteristics of the teacher and the child, but also on a series of factors such as: the behavioral tendency of the pupil (Birch \& Ladd, 1998), the relationships between the teacher and parents (Howes \& Matheson, 1992; Rydell, Bohlin, \& Thorell, 2005), the child's temperament and linguistic skills (Rudasill, Rimm- Kaufmann; Fumoto, Hargreaves, \& Maxwell, 2007), the baby's gender (Myers \& Pianta, 2008; Colwell \& Lindsey, 2003), the teacher's sense of efficacy (Hamre et al., 2008; Mashburn et al., 2008), the possession of an academic degree and possible disability in the pupil (Eisenhower, Blaker, \& Blacher, 2007). Nevertheless, the research on the teacher-child relationship is rarely extended to subjects with disability (Robertson et al., 2003). In this respect the Italian context is no different, even though big importance is given to the integration of disabled children, making it an essential element of the educational system. 
Relationship between the teacher and the child with autistic spectrum disorder

Communication, interaction with others and poverty of interest are among the most important difficulties of children with autistic spectrum disorder (ASD). Nowadays, a growing number of these children is educated within basic educational institutions (Dybvik, 2004; Keen \& Ward, 2004). However, it has to be pointed out that school did not develop adequate knowledge and services to satisfactorily cope with the needs pupils with ASD. Indeed, the educational methods teachers employ with autistic subjects are still little known and, therefore, little shared. In a nutshell, the education of such subjects remains a little-investigated area of the scholastic activity (Humphrey \& Lewis, 2008). On the other hand, class teachers acknowledge that they are not adequately trained to provide the correct support for this kind of pupils (Robertson, Chamberlain \& Kasari, 2003).

This issue has been partly addressed by establishing the role of the support teacher. These supporting teachers have become the most important instrument to facilitate both the insertion and the integration of pupils with disabilities and the resulting specific educational needs (McVittie, 2005; Howes, 2003; Hemmingsson et al., 2003). The law provides that children with ASD must be supported in the classroom, receiving adequate assistance from support teachers. Nevertheless, despite the presence of support teachers for children with special educational needs, the research that had been carried out, even when referring to ASD children, was scarce and sporadic. Basically, no reliable data concerning the effectiveness of programs aimed at promoting cognitive and social skills has ever been shown (Howes, 2003). There is no doubt that the presence of support teachers can raise the children's satisfaction concerning the school work, improving their attention, their motivation and their behavior (Blatchford et al., 2009a). In particular, the support teacher can, on one hand, reduce possible tensions between the child with ASD and other pupils or with the class teacher (Emam \& Farrell, 2009). On the other hand, the support teacher becomes an important figure, especially in case the child with ASD has, for any reason, to change her class teacher (Alston \& Kilham, 2004). In other words, the support teacher, being a constant reference point, provides the child with continuity, protecting him from changes and unexpected events during the educational program. The presence of the support teacher is also favorable concerning academic achievements, if compared to ASD children without support (Blatchford et al., 2009b).

Besides positive effects, the presence of a support teacher entails a number of other aspects which deserve attention. First of all, some authors underline that children with ASD have poor and sometimes insubstantial achievements deriving from the direct action of the support teacher (Howes, 2003; Blatchford et al., 2009a). Moreover, they point out that the support teacher's presence in the classroom may reduce the class 
teacher's attention towards the child with ASD (Blatchford et al., 2009b). It's not unusual that the class teacher addresses instructions and remarks not towards the child with ASD (that often have a personal support teacher) but towards the support teacher of the child (Hemmingsson et al., 2003). Howes (2003) further remarks that having a support teacher could lead children with ASD to reduce their autonomy. Finally, McVittie (2005) observes that pupils who have available a support teacher are generally exposed to the risk of being socially excluded by classmates and thus marginalized. As for children with ASD, such a situation would be particularly negative, due to their peculiar difficulties with social skills (Symes \& Humphrey, 2010). In addition to this, it should be added that not every class teacher accepts the presence of a second teacher favorably. This second teacher would be in a subordinate position, if compared to the class teacher, despite of having a postgraduate qualification. Morewood (2009) argues that, in order to allow the support teachers to operate effective interventions on the pupils entrusted to their care, it is crucial that their colleagues and the school head respect the support teachers' role and recognize their educational action.

In the light of such observations, the present study aims at analyzing and comparing the perceptions from the class teacher and the support teacher concerning their relationship both with ASD subjects and with typically developing pupils. To this end, the socio-demographic and professional characteristics of the involved teachers were taken into account. Moreover, the children's perceptions concerning the autistic children's adaptive abilities were considered.

\section{METHOD}

\section{Participants}

14 Classes were involved in the study. One child with autistic spectrum disorder is present in each class. The ASD children group is composed of 11 males and 2 females (Age in month: $M=90.07, D S=19.36$; range: $57-118$ ) equally divided between high and low functioning. For each class, four typically-developing children were drawn, for a total of 56 pupils (28 males and 28 females; age in months: $M=80.36 ; D S=18.33$; range: 49-107). For each class, two female teachers were involved: the regular class teacher and the support teacher (Tab.1).

\section{Instruments}

The relationships were investigated throughout the STRS (Pianta, 1994; Fraire et al., 2008, in press), a questionnaire addressed to teachers. The questionnaire, in its Italian version, is composed of 22 items which relate to three typical dimensions of the perceived relationship with the pupil (Conflict, Closeness and Dependency). 
The social characteristics of the students are investigated throughout a peer assessment (Masten et al, 1985), which is composed of eight questions. All of the pupils from the involved classes took part in the assessment, thus ensuring the validity of the social perception measurements (Cairns \& Cairns, 1994). Thus, for each cited aspect of the school life, we evaluated if (and by how many classmates) the autistic child had been mentioned.

Tab. 1. Children's and (class and support) teachers' Socio-Demographic data

\begin{tabular}{|c|c|c|c|c|c|}
\hline & & & Mean & Std. Dev. & Range \\
\hline \multirow{7}{*}{ 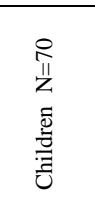 } & \multicolumn{2}{|c|}{ Age in Months } & 83.08 & 18.943 & $49-118$ \\
\hline & \multirow{2}{*}{ Gender } & Male & $55.7 \%$ & & \\
\hline & & Female & $44.3 \%$ & & \\
\hline & \multirow{4}{*}{$\begin{array}{l}\text { Attended } \\
\text { year }\end{array}$} & Preschool & $21.4 \%$ & & \\
\hline & & First & $21.4 \%$ & & \\
\hline & & Second & $35.7 \%$ & & \\
\hline & & Third & $21.4 \%$ & & \\
\hline \multirow{5}{*}{ 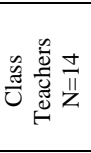 } & \multicolumn{2}{|c|}{ Class Teacher's Age } & 50.17 & 5.573 & $38-57$ \\
\hline & \multirow{2}{*}{$\begin{array}{c}\text { Educational } \\
\text { Qualification }\end{array}$} & Primary school teaching certificate & $78.57 \%$ & & \\
\hline & & Degree & $21.43 \%$ & & \\
\hline & \multicolumn{2}{|c|}{ Years of experience } & 28.29 & 9.025 & $4-40$ \\
\hline & \multicolumn{2}{|c|}{ Teaching hours per week carried out in the class } & 19.79 & 4.964 & $11-25$ \\
\hline \multirow{5}{*}{ 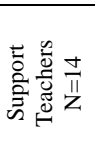 } & \multicolumn{2}{|c|}{ Support Teacher's Age } & 37.64 & 10.817 & $24-55$ \\
\hline & \multirow{2}{*}{$\begin{array}{l}\text { Educational } \\
\text { Qualification }\end{array}$} & Primary school teaching certificate & $42.86 \%$ & & \\
\hline & & Degree & $57.14 \%$ & & \\
\hline & \multicolumn{2}{|c|}{ Years of experience } & 13.22 & 11.283 & $0.42-30$ \\
\hline & \multicolumn{2}{|c|}{ Teaching hours per week carried out with the child } & 18 & 4.858 & $12-25$ \\
\hline
\end{tabular}

Skills in children with autistic spectrum disorder were detected by the support teacher throughout the ABI (Brown \& Leigh, 1987), a test which evaluates the adaptive behavior of the disabled subject, encompassing five main areas (Self-Care Skills, Communication skills, Social skills, Academic skills, Occupational skills). An especially deep analysis concerning the social skills dimension was carried out.

The pupils' academic achievement and commitment to schooling were evaluated by the class teacher and by the support teacher with a 3-point Likert scale (low, medium, high level).

\section{RESULTS AND DISCUSSION}

Relationships with typically developing children are perceived by the class teacher as being averagely good, featuring low Conflict and Dependency levels and high Closeness levels.

Such perception differs from the one concerning the relationship with ASD children in a statistically significant way. Indeed, the relationship with autistic spectrum disorder children is characterized by higher Conflict levels $(t=-3.317 ; D F=14.931$; $p<0.01)$ and lower Closeness scores $(t=5.638 ; D F=65 ; p<0.001)$. With regards to Dependency levels, relationships with ASD children, as experienced by the class teacher, are comparable to relationships with their classmates (Tab.2). 
The support teacher, concerning children with ASD, describes relationships which are connoted by mid-low levels of Conflict and Dependency and adequate levels of Closeness. In reference to children with high and low functioning ASD, the scores which were recorded by the support teacher on the three STRS dimensions are similar.

In the evaluation by support teachers, relationships with autistic children have, on the average, a higher quality if compared to those evaluated by class teachers. Support teacher report, indeed, higher levels of closeness and lower levels of conflict, if compared to their colleagues who work with the class group.

When comparing the class teacher's perception of the relationship with the one by the support teacher, a statistically significant positive correlation can be observed, but only for the Conflict scale $(r=0.769 ; p<0.01)$. Class teachers and support teachers can thus evaluate the intimate and affective aspects of the relationships with the autistic child in different manners, and the same is true for help requests and the child's autonomy level.

Tab. 2. Descriptive statistics: STRS dimensions in the two teachers' perception concerning the two groups of pupils: Children with ASD and Typically-developing children. The support teacher has filled out the STRS only for ASD children

\begin{tabular}{|c|c|c|c|c|c|c|}
\hline & \multirow{2}{*}{ STRS } & \multicolumn{2}{|c|}{$\operatorname{ASD}(n=14)$} & \multicolumn{2}{|c|}{$\begin{array}{l}\text { Typically-developing Children } \\
\qquad(\mathrm{n}=56)\end{array}$} & \multirow[t]{2}{*}{$\begin{array}{c}\text { Sig. } \\
\text { (Student's } t \text { ) }\end{array}$} \\
\hline & & Mean (S.D.) & Range* & Mean (S.D.) & Range* & \\
\hline \multirow{3}{*}{$\begin{array}{l}\text { Class } \\
\text { Teacher }\end{array}$} & Conflict & $21.46(7.96)$ & $10-32$ & $13.72(5.51)$ & $10-30$ & $\mathrm{p}<0.01$ \\
\hline & Closeness & $23.42(4.89)$ & $15-30$ & $33.11(5.49)$ & $18-40$ & $\mathrm{p}<0.001$ \\
\hline & Dependancy & $8.29(3.67)$ & $4-14$ & $7.14(3.41)$ & $4-18$ & - \\
\hline \multirow{3}{*}{$\begin{array}{l}\text { Support } \\
\text { Teacher }\end{array}$} & Conflict & $18.07(8.45)$ & $10-33$ & & & \\
\hline & Closeness & $25.38(7.93)$ & $14-40$ & & & \\
\hline & Dependancy & $9.21(3.19)$ & $5-15$ & & & \\
\hline
\end{tabular}

* Theoretical Minimum and Maximum scores: Conflict 10-50, Closeness: 8-40, Dependency: 4-20

Taking into account the internal relations between the STRS scales, which were filled out by the class teachers (Tab.3), with regards to typically developing children's scores, a significant direct correlation between the Dependency scale and the Conflict scale can be observed $(r=0.626 ; p<0.001)$. Such data is coherent with what was reported by previous studies (Pianta, 2001; Fraire et al., in press; Koomen et al., 2012). On the other hand, among ASD children a positive correlation between the Dependency and the Closeness dimensions emerges $(r=0.607, p<0.05)$.

It is interesting to note that the Dependency assumes different meanings within the two different kinds of relationships. As for relationships with typicallydeveloping children, Dependency positively correlates with Conflict: here, both characterize "negative" relational dimensions. On the contrary, with regards to children with ASD, Dependency correlates with Closeness, which is a "positive" relational dimension. Such data could be explained as follows: the difficulties shown by autistic subjects, which cause the relationship to be conflicting, are not perceived by teachers as Dependency-correlated. These latter aspects (such as unnecessary requests of attention, difficulties of separation from the adult) would be rather connected with affinity and 
communication. Concerning the support teacher, no significant internal correlations between the STRS scales can be observed (Tab.3). Thus, it seems that the three dimensions have a particular meaning for the class teacher who evaluates her relationship with ASD children.

Tab. 3. Internal correlations between STRS scales for class teachers and for support teachers

\begin{tabular}{lcccc}
\hline & \multicolumn{2}{c}{ CLASS TEACHER } & \multicolumn{2}{c}{ SUPPORT TEACHER } \\
\hline \multicolumn{1}{c}{ Typically- Dev. } & Conflict & Closeness & Conflict & Closeness \\
\hline Conflict & 1 & -.149 & & \\
Closeness & -.149 & 1 & & \\
Dependancy & $.626^{* *}$ & .075 & Conflict & Closeness \\
\hline \multicolumn{1}{c}{ ASD } & Conflict & Closeness & 1 & -.169 \\
\hline Conflict & 1 & -.365 & -.169 & 1 \\
Closeness & -.365 & 1 & .182 & .459 \\
Dependancy & .374 & $.607^{*}$ & &
\end{tabular}

The analysis also considers the possibility that the perception of the relational dimensions is connected to some of the characteristics of the class teacher (such as age and teaching years). Concerning this issue, it can be noted a significant association only with regards to relationships with typically-developing pupils (Tab.4).

The younger and more inexperienced the teacher, the higher the levels of Conflict and Dependency in the relationships. Moreover, the reported Closeness scores increase with the years of teaching. On the other hand, the teacher's characteristic does not impact on the perception of the relationship with autistic children. Similarly, the support teacher's professional and personal features do not seem to be connected with any of the three dimensions concerning the relationship with ASD children, which were evaluated through the STRS.

Furthermore, some socio-demographic characteristics and the adaptive abilities of the autistic child have been considered, in order to understand how these features could be associated to the teachers' perception of the relationship (Tab.4).

The autistic child's age does not correlate with the perception of the relational dimensions for both kinds of teachers. On the contrary, data concerning relationships with their typically-developing classmates show higher scores on the perceived Closeness scales with older children $(r=0.372 ; p<0.05)$. Such discrepancy could be linked to the characteristics of the autistic disorder. Indeed, communicative and relational impairments in ASD children prevent higher levels of intimacy, trust and sharing.

Evaluations concerning academic achievements and commitment to schooling in pupils with autistic disorder have been carried out separately by the two kinds of teachers (Tab.2). The scores concerning achievements are correlated $(r=0.592 ; p<0.05)$. The amount of statistically significant correlations between academic achievement and the STRS dimensions varies with the teacher who evaluates the relationship. As for the support teacher, achievements positively correlate with the Dependency scale $(r=0.553$; 
$p<0.05)$, while the commitment inversely correlates with the Conflict scale $(r=-0,723$, $p<0.01)$. Thus, the level of commitment and academic achievement in students with autistic spectrum disorders has an influence on the quality of the relationship with such pupils. On the contrary, for the class teacher no correlations can be observed between the perception of the relationship with autistic children and the evaluation of their achievement and commitment.

However, such associations are significant with regards to the perception of the experienced relation with typically-developing children: class teacher consider higher academic achievement in pupils as being concurrent with low-conflict relationships (achievement: $r=-0.315 ; p<0.05$; commitment: $r=-0.273 ; p<0.05$ ). This discrepancy between the two kinds of teachers could be linked to the different role experienced in the relationship with ASD children. The academic achievement only impacts on the relationship as perceived by the support teacher, and not by the class teacher: this underlines how, for the former, achieving educational goals represents a relevant aim, in order to outline her relationship with the child with autistic disorder.

Tab. 4. Correlations between STRS dimensions, demographic characteristics, social and academic skills of the child

\begin{tabular}{|c|c|c|c|c|c|c|c|c|c|c|}
\hline & & \multicolumn{5}{|c|}{ Class Teacher } & \multirow{2}{*}{\multicolumn{4}{|c|}{$\begin{array}{l}\text { Support Teacher } \\
\text { ASD Children } \\
\end{array}$}} \\
\hline & & Typicall & Dev. C & dren & ASD & Idren & & & & \\
\hline & & 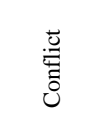 & 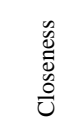 & 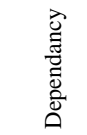 & 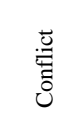 & $\begin{array}{l}\tilde{w} \\
\tilde{0} \\
\tilde{D} \\
\dot{0} \\
\tilde{0}\end{array}$ & 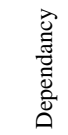 & 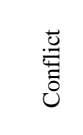 & 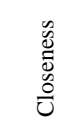 & 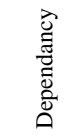 \\
\hline \multirow{2}{*}{ 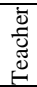 } & Age of the teacher & $-.530^{* *}$ & .204 & $-.412^{* *}$ & -.044 & .211 & .331 & .034 & .303 & -.071 \\
\hline & Years of teaching & $-.394^{* *}$ & $.311^{*}$ & $-.296^{*}$ & .183 & .226 & .385 & .007 & .339 & -.110 \\
\hline \multirow{3}{*}{ 营 } & Age of the child & -.039 & $.372^{*}$ & -.050 & .287 & .301 & .197 & .307 & .308 & -.234 \\
\hline & Achievement & $-.315^{*}$ & .247 & -.238 & -.040 & .127 & -.081 & -.023 & .198 & $.553^{*}$ \\
\hline & Commitment & $-.273^{*}$ & .124 & -.182 & -.209 & .412 & .022 & $-.723^{* *}$ & .071 & -.106 \\
\hline \multirow{8}{*}{$\begin{array}{l}\frac{\vec{\pi}}{2} \\
\tilde{w} \\
\frac{\tilde{\sigma}}{U}\end{array}$} & Playing & .029 & .134 & -.057 & .001 & .225 & .235 & -.252 & $.565^{*}$ & .324 \\
\hline & Practice in classroom & -.039 & .197 & -.080 & .223 & -.054 & .320 & -.105 & .147 & .305 \\
\hline & Disrupting & $.639^{* *}$ & .083 & $.301^{*}$ & .369 & -.525 & -.148 & .027 & .062 & -.018 \\
\hline & Helping & -.224 & .147 & -.233 & .192 & .202 & .499 & -.001 & .454 & .406 \\
\hline & Quarreling & $.611^{* *}$ & .041 & $.277^{*}$ & .322 & -.166 & .130 & -.119 & .491 & .124 \\
\hline & Being Isolated & .033 & .194 & $.301^{*}$ & .371 & -.014 & .441 & .272 & .213 & .408 \\
\hline & $\begin{array}{l}\begin{array}{l}\text { Getting along with the } \\
\text { teacher }\end{array} \\
\end{array}$ & -.259 & .181 & -.213 & .222 & .185 & .401 & -.219 & $.647^{*}$ & .294 \\
\hline & Being teased & .067 & .046 & .092 & .281 & -.263 & .047 & -.056 & .258 & -.088 \\
\hline \multirow{5}{*}{$\bar{q}$} & Self-Care Skills & & & & -.012 & .261 & -.023 & .008 & .484 & .138 \\
\hline & Communication skills & & & & .303 & -.400 & -.179 & -.086 & .259 & -.206 \\
\hline & Social Skills & & & & -.154 & .198 & -.066 & -.438 & $.598^{*}$ & -.075 \\
\hline & Academic Skills & & & & .331 & .080 & .183 & .082 & .458 & -.039 \\
\hline & Occupational Skills & & & & -.102 & .175 & -.035 & -.310 & .440 & -.091 \\
\hline
\end{tabular}


Throughout the ClassPlay, social skills have been assessed as a percentage of the nominations which classmates gave to the children who were involved in the research, for the different proposed situations. The levels of Conflict and Dependency perceived by the class teacher in the relationship with typically developing children are positively correlated with the number of received nominations within the "disrupting" (Conflict: $r=0.639 ; p<0.001$; Dependency: $r=0.301 ; p<0.05)$ and "quarreling" (Conflict: $r=0,611, p<0,001$; Dependency: $r=0.277 ; p<0.05$ ) dimensions.

Moreover, scores relating to Dependency are connected to the number of nominations that characterize the child as "isolated" by classmates $(r=0.301 ; p<0.05)$. On the other hand, concerning ASD children, for the class teacher no STRS dimension correlates with the percentage of nominations received from classmates. On the contrary, the perception of the support teacher about the relationship with autistic children is associated, within the Closeness dimension, to positive aspects such as "playing with classmates" $(r=0.565 ; p<0.05)$ and "getting along with teachers" $(r=0.647 ; p<0.05)$ : the more autistic children are chosen by classmates in such situations, the more the teacher perceives higher levels of affection and open communication with the pupil.

Such results are coherent with what emerges from the analysis of social skills, surveyed with the ABI questionnaire. A significant correlation can be noted: higher social skills relate with higher levels of Closeness in the perception of the support teacher $(r=0.598 ; p<0.05)$. As for the class teacher, the different relational aspects do not correlate with any level of social skills. Other ABI scales do not correlate with the two teachers' perception of the relationship.

\section{CONCLUSIONS}

From the carried out research, different modalities in establishing and perceiving the relationship with ASD pupils between class teachers and support teachers seem to emerge. The two kinds of teacher differently evaluate the intimate and affective dimension of the relationship with the autistic child, their help requests and their levels of autonomy. The class teacher perceives the relationship with autistic children as more conflicting, and as being characterized by lower levels of closeness, if compared to the ones she established with other children in the class. The support teacher's perception of the relationship with ASD children is affected by their social skills, academic achievements and commitment to schooling. On the other hand, for the class teacher such connections can be observed only with regard to the control group, and not with regard to the relationship with autistic children. Thus, social skills and academic achievements are dimensions which impact only on the support teacher's perception of the relationship. The relation between autistic children and class teachers seems to be less focused on the child's specific features, less individualized and less intimate.

It should be noted that the personal characteristics of the children in the control group and their academic skills have an influence on the class teacher's perception of the relationship. Such difference between the two examined groups of children seems to confirm the following hypothesis: the class teacher establishes and perceives the relationship with ASD children in a different manner. It's like the presence 
of the support teacher leads the class teacher towards a lower relational and educational responsibility, thus yielding a higher distance and a lower engagement.

This difference in the way the relationship is experienced is confirmed by the comparison with the classmates' perception concerning the social skills of the impaired subject. Therefore, the observed results seem to underline a deeper sensitivity and attention by the support teacher towards children with ASD, if compared to the class teacher, who has to manage the whole group of children. Since a real integration in the class group and, more generally, the pupil's well being are primarily reliant on the relationship with the teacher, the establishment of good relations with both the educational figures becomes crucial for the autistic child. The support teacher is mainly aware of the strengths and the weaknesses of the pupil, and is designated to directly fulfill her educational needs. She is a fundamental figure in letting the class teacher know the child's actual skills. Thereby, she can favor the establishment of a more positive relationship with the curricular teacher and the other classmates, thus promoting the autistic child's well being within the classroom.

\section{REFERENCES}

Alston, J., \& Kilham, C. (2004). Adaptive education for students with special needs in the inclusive classroom. Australian Journal of Early Childhood, 29, 24-33.

Birch, S.H., \& Ladd, G.W. (1998). Children's interpersonal behaviors and the teacher-child relationship. Developmental Psychology, 34(5), 934-946.

Blatchford, P., Bassett, P., Brown, P., Martin, C., Russell, A., \& Webster, R. (2009a). Deployment and Impact of Support Staff Project. London: DCSF.

Blatchford, P., Bassett, P., Brown, P., \& Webster, R. (2009b). The effect of support staff on pupil engagement and individual attention. British Educational Research Journal, 35, 661686.

Bowlby, J. (1988). A secure base: Parent-child attachment and healthy human development. New York: Basic Books.

Brown, L., \& Leigh, J.E. (1987). ABI Adaptive Behavior Inventory. Test di valutazione del comportamento adattivo nell 'handicappato. Trento: Erickson.

Cairns, R.B., \& Cairns, B.D. (1994). Lifelines and risks: Pathways of youth in our time. Cambridge, UK: Cambridge University Press.

Colwell, M.J., \& Lindsey, E.W. (2003). Teacher-child interactions and preschoolers perceptions of self and peers. Early Child Development and Care, 173, 249-258.

Dybvik, A. C. (2004). Autism and the inclusion mandate. Education Next, 4, 42-49.

Eisenhower, A.S., Blaker, B.L., \& Blacher, J. (2007). Early student-teacher relationships of children with and without intellectual disability: Contributions of behavioral, social, and self-regulatory competence. Journal of School Psychology, 45, 363-383.

Emam, M.M., \& Farrell, P. (2009). Tensions experienced by teachers and their views for pupils with autism spectrum disorders in mainstream schools. European Journal of Special Needs Education, 24, 407-422.

Fraire, M., Longobardi, C., \& Sclavo, E. (2008). Contribution to Validation of the Student-Teacher Relationship Scale (STRS Italian Version) in the Italian Educational Setting. European Journal of Education and Psychology, 1(3), 49-59. 
Fraire, M., Longobardi, C., Prino L.E., Sclavo E., \& Settanni, M. (in press). Examining the Student-Teacher Relationship Scale in the Italian Context: A Factorial Validity Study. in press

Fumoto, H., Hargreaves, D.J., \& Maxwell, S. (2007). Teachers' perceptions of their relationships with children who speak English as an additional language in early childhood settings. Journal of Early Childhood Research, 5(2), 135-153.

Hamre, B.K., Pianta, R.C., Downer, J.T., \& Mashburn, A.J. (2008). Teachers' perceptions of conflict with young students: Looking beyond problem behaviors. Social Development, 17(1), 115-136.

Hemmingsson, H., Borell, L., \& Gustavsson, A. (2003). Participation in school: school assistants creating opportunities and obstacles for pupils with disabilities. Occupation, Participation and Health, 23, 88-98.

Howes, A. (2003). Teaching reforms and the impact of paid adult support on participation and learning in mainstream schools. Support for Learning, 18, 147-153.

Howes, C, \& Matheson, C.C. (1992). Sequences in the development of competent play with peers: Social and social pretend play. Developmental Psychology, 28, 961-974.

Humphrey, N., \& Lewis, S. (2008). "Make me normal": the views and experiences of pupils on the autistic spectrum in mainstream secondary schools. Autism: an International Journal of Research and Practice, 12, 39-62.

Keen, D., \& Ward, S. (2004). Autistic spectrum disorder: a child population profile. Autism, 8, 3948.

Koomen, H.M.Y., Verschueren, K., van Schooten, E., Jak, S., \& Pianta, R.C. (2012). Validating the Student-Teacher Relationship Scale: Testing factor structure and measurement invariance across child gender and age in a Dutch sample. Journal of School Psychology, 50, 215-234.

Mashburn, A.J., Pianta, R.C., Hamre, B.K., Downer, J.T., Barbarin, O., Bryant, D., Burchinal, M., Clifford, R., Early, D.M., \& Howes, C. (2008). Measures of classroom quality in prekindergarten and children's development of academic, language, and social skills. Child Development, 79(3), 732-749.

Masten, A.S., Morrison, P., \& Pellegrini, D.S. (1985). A revised class play method of peer assessment. Developmental Psychology, 21(3), 523-533.

McVittie, E. (2005). The role of the teaching assistant: an investigative study to discover if teaching assistants are being used effectively to support children with special educational needs in mainstream schools. Education 3-13: International Journal of Primary, Elementary and Early Years Education, 33(3), 26-31.

Morewood, G. (2009). Seeing the big picture: organizing effective whole-school deployment of support staff. Becta Collaboration, 8, 8-13.

Myers, S.S., \& Pianta, R.C. (2008). Developmental commentary: Individual and contextual influences on student-teacher relationships and children's early problem behaviors. Journal of Clinical Child \& Adolescent Psychology, 37(3), 600-608.

Pianta, R.C. (1994). Patterns of relationship between children and kindergarten teachers. Journal of School Psychology, 32(1), 15-31.

Pianta, R.C. (1999). Enhancing relationships between children and teachers. Washington, DC: American Psychological Association.

Pianta, R.C. (2001). Student-Teacher Relationship Scale: Professional manual. Odessa, FL: Psychological Assessment Resources, Inc.

Pianta, R.C., Steinberg, M.S., \& Rollins, K.B. (1995). The first two years of school: Teacher-child relationships and deflections in children's classroom adjustment. Development and Psychopathology, 7(2), 295-312. 
Robertson, K., Chamberlain, B., \& Kasari, C. (2003). General education teachers' relationship with included students with autism. Journal of Autism and Developmental Disorders, 33, 123-130.

Rudasill, K.M., Rimm-Kaufman, S., Justice, L., \& Pence, K. (2006). Temperament and language skills as predictors of teacher-child relationship quality in preschool. Early Education and Development, 17(2), 271-291.

Rydell, A., Bohlin, G., \& Thorell, L.B. (2005). Representations of attachment to parents and shyness as predictors of children's relationships with teachers and peer competence in preschool. Attachment and Human Development, 7, 187-204.

Symes, W., \& Humphrey, N. (2010). Peer-group indicators of social inclusion for pupils with autistic spectrum disorders in mainstream secondary schools: a comparative study. School Psychology International, 31(5), 478-494.

Received: November 21th, 2012

Modifications Received: December 3rd, 2012

Accepted: December 4th, 2012 